Subscriber access provided by Caltech Library

\title{
Article
}

\section{Olefin Hydroarylation Catalyzed by (Pyridyl-Indolate)Pt(II) Complexes: Catalytic Efficiencies and Mechanistic Aspects}

Benjamin A. Suslick, Allegra L. Liberman-Martin, Truman C. Wambach, and T. Don Tilley

ACS Catal., Just Accepted Manuscript • Publication Date (Web): 18 May 2017

Downloaded from http://pubs.acs.org on May 19, 2017

\section{Just Accepted}

"Just Accepted" manuscripts have been peer-reviewed and accepted for publication. They are posted online prior to technical editing, formatting for publication and author proofing. The American Chemical Society provides "Just Accepted" as a free service to the research community to expedite the dissemination of scientific material as soon as possible after acceptance. "Just Accepted" manuscripts appear in full in PDF format accompanied by an HTML abstract. "Just Accepted" manuscripts have been fully peer reviewed, but should not be considered the official version of record. They are accessible to all readers and citable by the Digital Object Identifier (DOI®). "Just Accepted" is an optional service offered to authors. Therefore, the "Just Accepted" Web site may not include all articles that will be published in the journal. After a manuscript is technically edited and formatted, it will be removed from the "Just Accepted" Web site and published as an ASAP article. Note that technical editing may introduce minor changes to the manuscript text and/or graphics which could affect content, and all legal disclaimers and ethical guidelines that apply to the journal pertain. ACS cannot be held responsible for errors or consequences arising from the use of information contained in these "Just Accepted" manuscripts. 


\section{INTRODUCTION}

Catalytic $\mathrm{C}-\mathrm{C}$ bond-forming processes are important for efficient utilization of abundant feedstock chemicals. These methods are critical to the industrial-scale syntheses of alkyl arene products, which are incorporated into many plastics and fine chemicals on an enormous scale. For example, polystyrene, which is manufactured from ethylbenzene, was consumed at an annual rate of $1.2 \times 10^{7}$ tons/year from 20002010. ${ }^{1}$ While methods exist to couple alkyl and aryl fragments using molecular catalysis (e.g. cross coupling ${ }^{2}$ ), such systems often require the use of activated reagents such as $\mathrm{ArSnR}_{3}$ or ArZnX, which generate additional synthetic steps. Moreover, these methods are atom inefficient and generate stoichiometric waste.

Given recent advances in $\mathrm{C}-\mathrm{H}$ functionalization chemistry, ${ }^{3}$ reactions that can directly couple aryl $\mathrm{C}-\mathrm{H}$ bonds and small molecules are feasible. In particular, the hydroarylation of carbon-carbon multiple bonds has garnered considerable attention over the last two decades. ${ }^{4}$ The initial developments of olefin hydroarylation catalyzed by $\mathrm{RuH}_{2}(\mathrm{CO})\left(\mathrm{PPh}_{3}\right)_{3}$ were described by Murai and coworkers ${ }^{5}$. Further mechanistic investigations with related $\mathrm{Ru}(\mathrm{II})^{6}$ and $\operatorname{Ir}(\mathrm{III})^{7}$ complexes illustrated that olefin insertion into a metal-aryl bond and arene $\mathrm{C}-\mathrm{H}$ activation are key mechanistic steps. ${ }^{5-7}$ Several recent reports have indicated that the hydroarylation of olefins to generate alkyl arenes ${ }^{4}$ can also be achieved with transition metal catalysts with $d^{8}$ electronic configurations (e.g., $\operatorname{Ir}(\mathrm{I}),^{8} \mathrm{Rh}(\mathrm{I}),{ }^{9,10}$ and

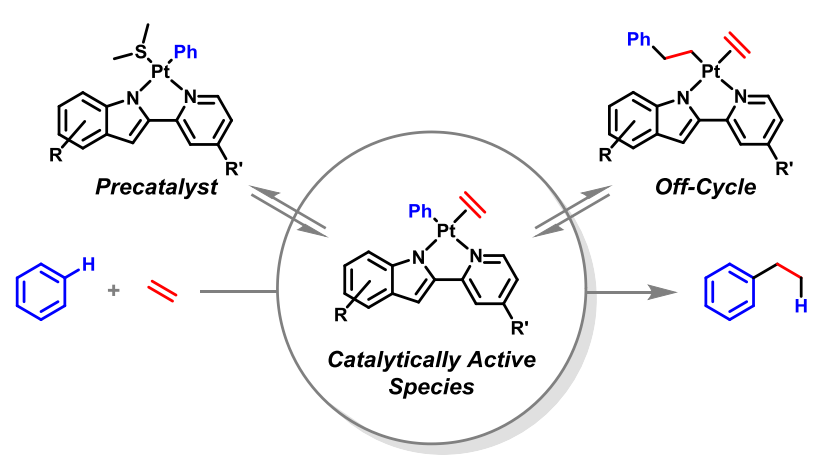

$\left.\operatorname{Pd}(I I)^{11}\right)$. It is worth noting that the mechanistic features of these systems have not been thoroughly elucidated.

Both cationic and neutral Pt(II) complexes supported by $4,4^{\prime}$ di-tert-butyl-2,2'-bipyridine ('bpy) ${ }^{12}$ or 2,2'-pyridyl-pyrrole $(\text { PyPyr })^{13}$ ligands, respectively, have recently been reported as hydroarylation catalysts. Unlike other $d^{8}$ metal catalysts, these systems operate with unactivated arene substrates that do not contain directing or coordinating functionalities, but the efficiencies of these catalysts are rather limited. ${ }^{12,13}$ In the latter context, it has been suggested that modification of the ancillary ligand donating ability could potentially improve the activity of Pt-based catalysts. ${ }^{14}$ However, there has not been a thorough study of ligand electronic effects for neutral Pt catalysts, even though these systems appear to exhibit higher selectivities for mono- (vs. poly-) alkylation, relative to cationic catalysts. ${ }^{15}$ Moreover, detailed investigations into complex degredation pathways have not been performed for the neutral $\mathrm{Pt}$ (II) systems. Determining the primary decomposition routes is necessary to design robust catalysts and elucidate potential additives that suppress unproductive processes.

We have previously reported the use of Pt complexes bearing a parent 2,2'-pyridyl-indolate (PyInd) ligand for the hydroarylation of norbornene. ${ }^{16}$ Herein, the synthesis and olefin hydroarylation activity of $\mathrm{Pt}(\mathrm{II})$ complexes of the type ( $\mathrm{N}-$ $\mathrm{N}) \mathrm{PtPh}\left(\mathrm{SR}_{2}\right)$ are described for a series of pyridyl-indolate complexes. The identification and isolation of several catalytic intermediates provide insight into the operative mechanism for 
hydroarylation. Additionally, differences in catalytic performance as a function of substituents on the $\mathrm{N}-\mathrm{N}$ ligand have been determined for a variety of olefin and arene substrates.

\section{RESULTS AND DISCUSSION}

Synthesis of Platinum Pyridyl-Indolate Complexes. A parent ligand bearing a $4^{\prime}-{ }^{t} \mathrm{Bu}$ group on the pyridyl moiety (1a) was chosen due to its solubility in hydrocarbons, as well as its diagnostic tert-butyl ${ }^{1} \mathrm{H}$ NMR resonance. Several highly-fluorinated derivatives were also synthesized (1) $\mathbf{b}$ and $\mathbf{1} \mathbf{c}$ ). To thoroughly probe the electronic effects of this ligand type on catalysis, a series of $(\mathrm{N}-\mathrm{N})$ ligands with various electron withdrawing or donating substituents (1d-1j) was synthesized using a procedure adapted from Wang and coworkers. ${ }^{17}$ Condensation of arylhydrazines with acetylpyridine afforded arylhydrazone intermediates. Treatment with neat polyphosphoric acid generated the desired substituted $\mathrm{N}-\mathrm{N}$ ligands (see Supporting Information, SI, Scheme S1).

The pyridyl-indolate ligands were incorporated into platinum complexes by reactions with $\left(\mathrm{SMe}_{2}\right)_{2} \mathrm{PtPh}_{2}$, to afford complexes of the type $(\mathrm{N}-\mathrm{N}) \mathrm{PtPh}\left(\mathrm{SMe}_{2}\right)(\mathbf{2 a - j}$, Scheme 1) which were purified by column chromatography. The analogous $\mathrm{SEt}_{2}$ complex, (Pylnd)PtPh(SEt $\left.{ }_{2}\right)(\mathbf{2 k})$, was generated by treatment of $\left[\left(\mu-\mathrm{SEt}_{2}\right) \mathrm{PtPh}_{2}\right]_{2}$ with $\mathbf{1 d}$ in benzene (Scheme 1$)$.

Scheme 1. Synthesis of Catalysts 2a-k.

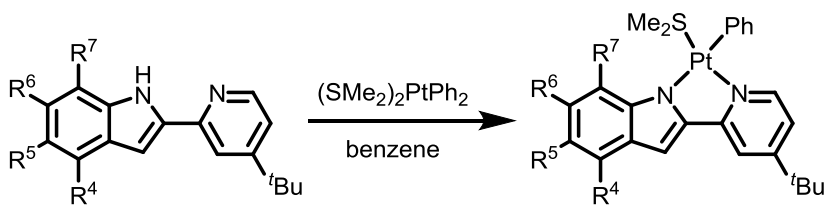

1a ('BuPyInd); $R^{4}, R^{5}, R^{6}, R^{7}=H$ 2a-c 1b ( ${ }^{t}$ BuPylnd-4,7- $\left.F_{2}\right) ; R^{4}, R^{7}=F ; R^{5}, R^{6}=H$ 1c ('BuPylnd-4,5,6,7-F $\left.F_{4}\right) ; R^{4}, R^{5}, R^{6}, R^{7}=F$

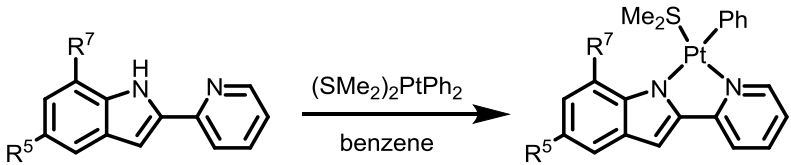

1d (Pylnd); $R^{5}, R^{7}=H$ $2 d-j$

1e $\left(\right.$ PyInd-5-MeO); $R^{5}=\mathrm{MeO} ; \mathrm{R}^{7}=\mathrm{H}$

1f (Pylnd-5-Me); $R^{5}=M e ; R^{7}=H$

19 (Pylnd-5-F); $R^{5}=F ; R^{7}=H$

1h (PyInd-5-Cl); $\mathrm{R}^{5}=\mathrm{Cl} ; \mathrm{R}^{7}=\mathrm{H}$

1i (Pylnd-5-Br); $\mathrm{R}^{5}=\mathrm{Br} ; \mathrm{R}^{7}=\mathrm{H}$

1j (Pylnd-7-Cl); $\mathrm{R}^{5}=\mathrm{H} ; \mathrm{R}^{7}=\mathrm{Cl}$

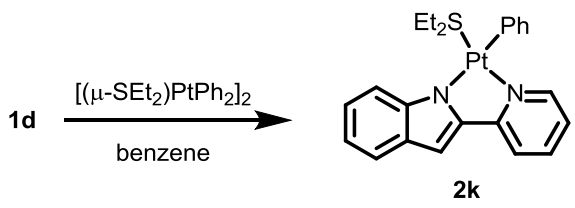

There are several diagnostic ${ }^{1} \mathrm{H}$ NMR resonances for complexes 2a-k. The $\mathrm{SMe}_{2}$ ligand of $\mathbf{2 a - j}$ appears as a singlet with broad ${ }^{195} \mathrm{Pt}$ satellites $\left(\delta \sim 2.30 \mathrm{ppm}, J_{\mathrm{PtH}} \sim 60 \mathrm{~Hz}\right.$ in dichloromethane- $d_{2}$ ). The $o$-aryl protons on the phenyl ligand in complexes 2a-k also exhibited ${ }^{195} \mathrm{Pt}$ coupling $\left(\delta \sim 7.60, J_{\mathrm{PtH}} \sim 35 \mathrm{~Hz}\right.$ in dichloromethane- $d_{2}$ ).
Single crystals of $\mathbf{2 a}$ were obtained by slow diffusion of pentane into a toluene solution of the complex at $-35^{\circ} \mathrm{C}$. Complex 2a displays the expected square planar geometry, and the indolate donor is positioned trans to the phenyl ligand (Figure 1). The bond lengths and angles are consistent with related $\mathrm{Pt}$ (II) complexes. ${ }^{14,18}$ The crystal structures of complexes $\mathbf{2 b}$ and $\mathbf{2 c}$ are similar (see SI, Figures S1 and S2).

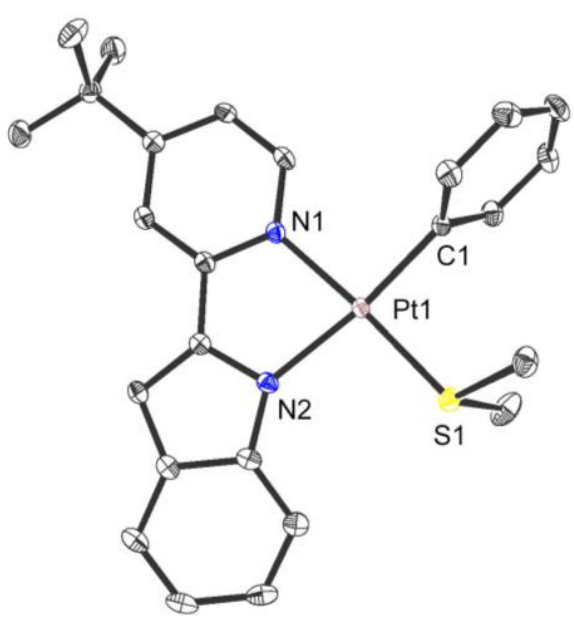

Figure 1. Crystal structure of $\mathbf{2 a}$, with hydrogen atoms omitted and thermal ellipsoids at $50 \%$ probability. Selected bond lengths $(\AA \AA)$ and angles $\left({ }^{\circ}\right)$ for $2 \mathrm{a}: \mathrm{C}(1)-\mathrm{Pt}(1)$ : 2.014(2), N(1)-Pt(1): 2.0529(18), $\mathrm{N}(2)-\mathrm{Pt}(1): 2.1030(17), \mathrm{S}(1)-\mathrm{Pt}(1): 2.2580(5), \mathrm{C}(1)-\mathrm{Pt}(1)-\mathrm{N}(1)$ : 93.41(8), C(1)-Pt(1)-S(1): 90.57(6), N(1)-Pt(1)-N(2): 79.32(7), $\mathrm{N}(2)-\mathrm{Pt}(1)-\mathrm{S}(1): 96.70(5)$.

Catalytic Hydroarylation with (N-N)Pt(SMe$) \mathrm{Ph}$ Complexes. Olefin hydroarylation studies were performed to determine the catalytic efficacy of complexes 2a-k. In the simplest hydroarylation reaction, neat benzene- $d_{6}$ and ethylene ( 1 atm) were heated to $100^{\circ} \mathrm{C}$ in the presence of the catalyst ( $2 \mathrm{a}$ k; $3.7 \mathrm{mM}$ ). The formation of the product, ethylbenzene- $d_{6}$ $\left(\mathrm{C}_{6} \mathrm{D}_{5} \mathrm{CH}_{2} \mathrm{CH}_{2} \mathrm{D}\right),{ }^{15}$ was monitored by ${ }^{1} \mathrm{H}$ NMR spectroscopy over the course of $46 \mathrm{~h}$ (see SI, Figure S3). With all catalysts tested, over-alkylation to form polyethylbenzenes was negligible $(<1$ turnover for all examples) as determined by ${ }^{1} \mathrm{H}$ NMR spectroscopy and GC-MS (see SI, Figure S4). Moreover, H(D) scrambling occurs only to a minor extent (by ${ }^{2} \mathrm{H}$ NMR spectroscopy).

Comparisons of total turnovers (after $24 \mathrm{~h}$ ) and initial rates (as approximated by the number of turnovers after $1 \mathrm{~h}$ ) for catalysts $\mathbf{2 a - k}$ are presented in Table 1 . In general, no catalyst decomposition was observed after $1 \mathrm{~h}$, by ${ }^{1} \mathrm{H}$ NMR spectroscopy. However at longer reaction times (> $24 \mathrm{~h}$ ), elemental $\mathrm{Pt}(0)$ was observed as a black precipitate as well as a thin film coating the walls of the reaction vessel. Moreover, minimal additional ethylbenzene production was observed beyond $24 \mathrm{~h}$ even upon exposure to additional ethylene, suggesting that this time point represents the catalysts' maximum lifespan.

Unfortunately, a clear trend of ethylbenzene formation as a function of the substitution pattern on the indolate fragment did not exist. In particular, substitution of the 5-position resulted in an inconclusive trend: both electron withdrawing ( $F$, 
$\mathrm{Cl}$ ) and electron donating (OMe) substituents resulted in an increase in initial rate and turnovers when compared to the parent catalyst 2d; however, a few notable patterns are discernible. The inclusion of a $4^{\prime}-{ }^{-} B$ mo moiety on the pyridyl fragment (2a vs. 2d) appeared to have no effect on product formation. The position of indolate substitution with $\mathrm{Cl}$ appeared to have a slight effect; complex $\mathbf{2 j}$ rapidly decomposed (resulting in reduced turnovers) whereas $\mathbf{2} \mathbf{h}$ was still catalytically active after $24 \mathrm{~h}$. Interestingly, replacing the ancillary $\mathrm{SMe}_{2}$ ligand (2d) for the slightly bulkier $\mathrm{SEt}_{2}$ donor (2k) resulted in a faster initial rate and higher turnover numbers. This superior performance may be attributed to the more labile $\mathrm{SEt}_{2}$ ligand being easier to exchange for ethylene, which is a key step in the hydroarylation mechanism.

Table 1. Catalytic Ethylene Hydroarylation with 2a-k.

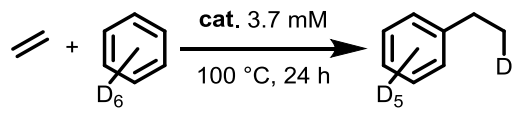

\begin{tabular}{|c|c|c|}
\hline Catalyst $^{a}$ & Total Turnovers ${ }^{b}$ & Initial Rate (TO / h) \\
\hline $2 a$ & $7.4 \pm 1.1$ & $1.0 \pm 0.02$ \\
\hline $2 b$ & $8.0 \pm 0.7$ & $0.7 \pm 0.4$ \\
\hline $2 c$ & $6.2 \pm 1.8$ & $0.7 \pm 0.2$ \\
\hline $2 d$ & $7.1 \pm 0.7$ & $1.4 \pm 0.1$ \\
\hline $2 e$ & $25.2 \pm 1.2$ & $5.0 \pm 0.2$ \\
\hline $2 f$ & $9.7 \pm 0.6$ & $1.8 \pm 0.5$ \\
\hline $2 \mathrm{~g}$ & $18.7 \pm 0.3$ & $2.7 \pm 0.2$ \\
\hline $2 \mathrm{~h}$ & $15.1 \pm 0.8$ & $2.6 \pm 0.1$ \\
\hline $2 \mathbf{i}$ & $8.6 \pm 0.2$ & $2.0 \pm 0.2$ \\
\hline $2 j$ & $2.9 \pm 0.6$ & $1.3 \pm 0.1$ \\
\hline $2 k$ & $20.0 \pm 0.4$ & $3.8 \pm 0.3$ \\
\hline
\end{tabular}

a Reaction conditions: Ethylene (1 atm), catalyst $(0.0026 \mathrm{mmol}, 3.7$ $\mathrm{mM})$, and $\mathrm{Si}\left(\mathrm{SiMe}_{3}\right)_{4}$ (internal standard) in benzene- $d_{6}(0.7 \mathrm{~mL})$ at $100{ }^{\circ} \mathrm{C}$. b Total turnovers at $24 \mathrm{~h}$ (average of triplicate experiments with standard deviations) determined by ${ }^{1} \mathrm{H}$ NMR spectroscopy. ${ }^{\mathrm{c}}$ Initial rate given as the turnover numbers after $1 \mathrm{~h}$.

To elucidate the relative influence of catalyst decomposition on catalytic efficiency, the relationship between ethylbenzene$d_{6}$ production (total turnovers, at $24 \mathrm{~h}$ ) and initial rate (turnovers at $1 \mathrm{~h}$ ) was compared (Figure 2). The data were fit to a linear regression with a slope of ca. 5.4. Ethylene concentration in solution (as determined by ${ }^{1} \mathrm{H}$ NMR spectroscopy) was relatively constant since the reaction vessel's head-space contained a significant excess of ethylene relative to catalyst loading. The linearity of this relationship, and the low value of the slope (far less than 24), implies that the product yield is mainly influenced by the initial reaction rate, and that the decomposition rate is roughly the same for all catalysts.

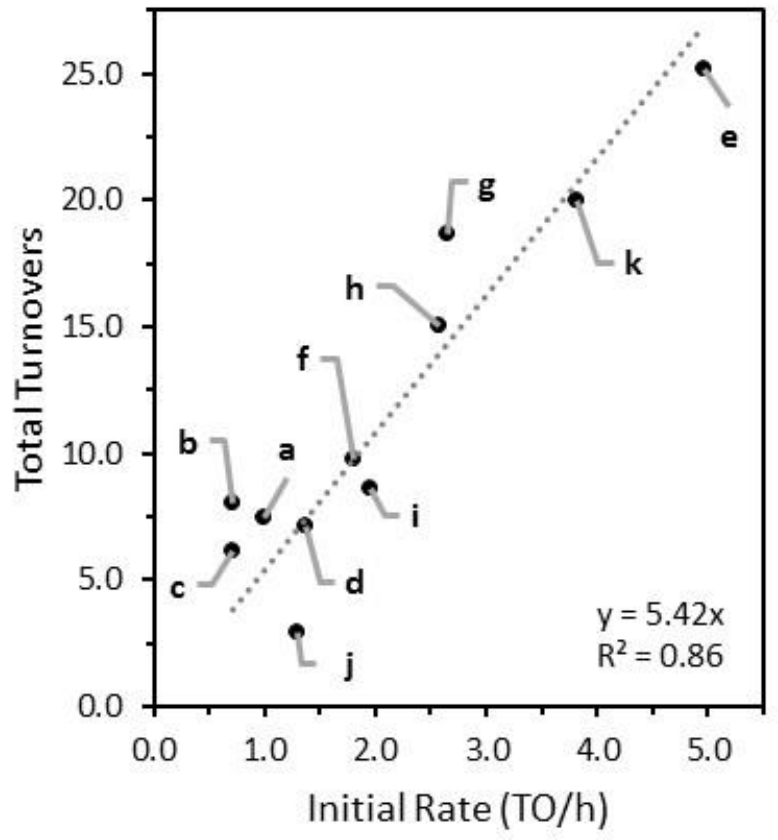

Figure 2. Plot of total turnovers of ethylbenzene- $d_{6}$ for catalysts $\mathbf{2 a - k}$ (measured at $24 \mathrm{~h}$ ) vs. the initial rate of ethylbenzene- $d_{6}$ formation (approximated as the turnovers after $1 \mathrm{~h}$ ). Error bars have been omitted for clarity. The dashed line is a linear fit of the data.

Table 2. Catalytic Propylene Hydroarylation with 2a-k.

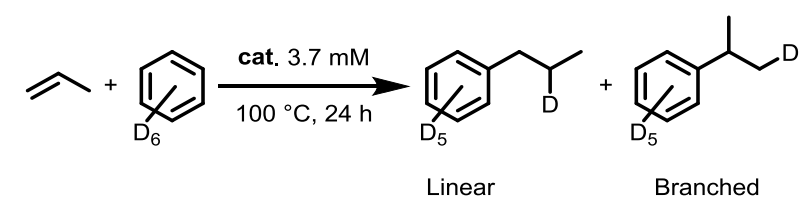

\begin{tabular}{ccc} 
Catalyst $^{\mathbf{a}}$ & Total Turnovers $^{\mathbf{b}}$ & Linear:Branched $^{\mathbf{c}}$ \\
\hline $\mathbf{2 a}$ & $5.6 \pm 0.4$ & $0.40 \pm 0.03$ \\
$\mathbf{2 b}$ & $2.4 \pm 0.1$ & $0.36 \pm 0.02$ \\
$\mathbf{2 c}$ & $2.5 \pm 0.2$ & $0.31 \pm 0.02$ \\
$\mathbf{2 d}$ & $5.2 \pm 0.4$ & $0.43 \pm 0.04$ \\
$\mathbf{2} \mathbf{e}$ & $19.8 \pm 2.3$ & $0.40 \pm 0.03$ \\
$\mathbf{2 f}$ & $8.5 \pm 0.7$ & $0.44 \pm 0.05$ \\
$\mathbf{2 g}$ & $6.4 \pm 0.2$ & $0.38 \pm 0.03$ \\
$\mathbf{2 h}$ & $8.6 \pm 0.2$ & $0.36 \pm 0.02$ \\
$\mathbf{2 i}$ & $7.5 \pm 0.6$ & $0.37 \pm 0.02$ \\
$\mathbf{2 j}$ & $0.6 \pm 0.03$ & $0.70 \pm 0.09$ \\
$\mathbf{2 k}$ & $8.0 \pm 1.0$ & $0.40 \pm 0.02$ \\
\hline
\end{tabular}

a Reaction conditions: Propylene (1 atm), catalyst $(0.0026 \mathrm{mmol}$, $3.7 \mathrm{mM})$, and $\mathrm{Si}\left(\mathrm{SiMe}_{3}\right)_{4}$ (internal standard) in benzene- $d_{6}(0.7 \mathrm{~mL})$ at $100{ }^{\circ} \mathrm{C}$. b Total turnovers at $24 \mathrm{~h}$ (average of triplicate experiments with standard deviations) determined by ${ }^{1} \mathrm{H}$ NMR spectroscopy and refers to the sum of the turnovers of $n$-propylbenzene$d_{6}$ and cumene- $d_{6} .{ }^{c}$ Determined as the ratio of TO $\mathrm{TO}_{\text {Linear }}: \mathrm{TO}_{\mathrm{Branched}}$.

Propylene hydroarylation was surveyed using catalysts $\mathbf{2 a - k}$ to determine the influence of ligand substitution on the ratio 
of anti-Markovnikov (linear) vs. Markovnikov (branched) products (Table 2). Reactions were performed for $24 \mathrm{~h}$ at $100{ }^{\circ} \mathrm{C}$, and product formation was monitored by ${ }^{1} \mathrm{H}$ NMR spectroscopy (see SI, Figure S5). Minimal variation in catalytic activity was observed for complexes $\mathbf{2} \mathbf{a}-\mathbf{k}$, and the overall activity of propylene hydroarylation was reduced compared to ethylene. Interestingly, complex $\mathbf{2 e}$ proved to be significantly more active than any of the other complexes tested, affording nearly 20 turnovers of propylene hydroarylation products after $24 \mathrm{~h}$.

Only a minimal variation in regioselectivity was observed for complexes 2a-k; the catalysts tended to form cumene- $d_{6}$ preferentially to $n$-propylbenzene- $d_{6}$ (i.e. Markovnikov selectivity), with a linear:branched ratio of ca. 0.40 . This selectivity is similar to that observed previously for other platinum hydroarylation catalysts. ${ }^{14,15,19}$ The linear/branched ratio remained constant over the course of the reaction (see SI, Figure S6), which suggested that the product formation rates for the two regioisomers are similar. Lastly, a comparison of total turnovers vs. initial rate for the hydroarylation of propylene with benzene$d_{6}$ suggested that the decomposition rates of catalysts $\mathbf{2 a - k}$ are similar (see SI, Figure S7).

Attempted catalytic hydroarylations of other substituted olefins with complex 2a were unsuccessful. While tert-butylethylene reacted with complex $2 a$ in benzene- $d_{6}$, the rate of product formation was far slower than was observed for reactions with propylene or ethylene (ca. 1 turnover of the hydroarylation products after $24 \mathrm{~h}$ ). Unfortunately, other olefins did not undergo hydroarylation: 1-octene rapidly isomerized to 2-octene, and cyclohexene did not undergo conversion over $24 \mathrm{~h}$. This suggests that the rate of isomerization catalyzed by these complexes is faster than the rate of productive hydroarylation, and internal olefins (2-octene and cyclohexene) are inert under the catalytic conditions.

The regiochemistry of $\mathrm{C}-\mathrm{H}$ bond cleavage during catalysis was probed with substituted arene substrates. Treatment of ethylene with catalyst $2 a$ in neat toluene yielded $8.4 \pm 0.3$ equivalents of ethyltoluenes after $24 \mathrm{~h}$ at $100{ }^{\circ} \mathrm{C}$, with $98 \%$ selectivity for meta- and para-products (as analyzed by GC; metaand para-ethyltoluene isomers could not be resolved). This suggests that the steric properties of the arene largely direct the $\mathrm{C}-\mathrm{H}$ activations. Mesitylene was employed as a substrate to determine whether more highly substituted arenes could also be functionalized. Indeed, catalyst 2 a converted mesitylene into the corresponding hydroarylation product $(8.8 \pm 0.4$ turnovers after $24 \mathrm{~h}$ at $100^{\circ} \mathrm{C}$ ), indicating that ortho-functionalization is viable.

Isotope Effects. To gain insight into the rate-determining step for catalysis, isotope effects on turnover numbers were examined. First, in separate experiments, the hydroarylation of ethylene using catalyst $\mathbf{2 a}$ in either benzene or benzene- $d_{6}$ gave $18.1 \pm 1.1$ and $7.4 \pm 1.1$ turnovers, respectively, after 24 hours at $100{ }^{\circ} \mathrm{C}$. The ratio of these two values $\left(\mathrm{TO}_{\mathrm{H}} / \mathrm{TO}_{\mathrm{D}}=2.4 \pm\right.$ $0.39)$ suggests that $C-H(D)$ activation is important in the turnover-limiting step. ${ }^{2,20}$ However, note that this comparison does not reflect a kinetic isotope effect as it is not calculated using rate constants and a rate law for this catalytic system has not been determined.
In a separate experiment, equimolar amounts of benzene and benzene- $d_{6}$ were used as neat substrates for ethylene hydroarylation with $\mathbf{2 a}$ as the catalyst (eq 1 ). In this experiment, hydroarylation could occur either through $\mathrm{C}-\mathrm{H}$ or $\mathrm{C}-\mathrm{D}$ activation to generate ethylbenzene or ethylbenzene- $d_{6}$, respectively, assuming that intermolecular isotopic scrambling does not occur. The product ratio was determined by quantitative ${ }^{13} \mathrm{C}\left\{{ }^{1} \mathrm{H}\right\}$ NMR spectroscopy after 24 hours at $100{ }^{\circ} \mathrm{C}$ (see SI, Figure S8). The terminal methyl carbons of the two products have different coupling patterns; for ethylbenzene, the $\mathrm{CH}_{3}$ resonance appears as a singlet, whereas the $\mathrm{CH}_{2} \mathrm{D}$ resonance appears as a triplet due to $C-D$ coupling. The ratio of these resonances provided a product ratio of ethylbenzene:ethylbenzene- $d_{6}$ of 1.4:1.0, which is consistent with hydroarylation occurring faster with benzene than with benzene- $d_{6}$.

The discrepancy in these values results from the fact that catalyst TON is a composite metric influenced by both reaction and decomposition rates and therefore is not a direct measure of $k_{\mathrm{H}}$ or $k_{\mathrm{D}}$. On the other hand, the isotopologue distribution as measured in the intermolecular competition experiment provides direct mechanistic information about the $\mathrm{C}-\mathrm{H}$ activation step. $^{20}$

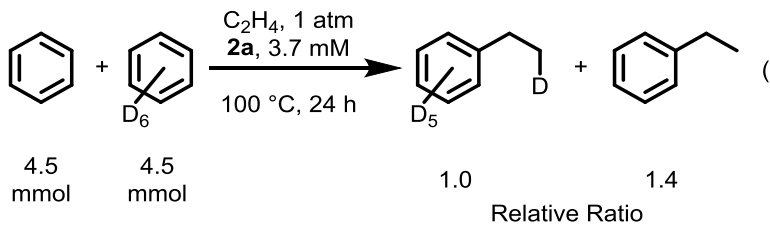
1)

Synthesis and Isolation of Potential Catalytic Intermediates. It has been suggested that complexes of the type $\left[\mathrm{L}_{2} \mathrm{Pt}\left(\mathrm{CH}_{2} \mathrm{CH}_{2} \mathrm{Ph}\right)\left(\mathrm{C}_{2} \mathrm{H}_{4}\right)\right]^{+}$are either catalytic intermediates in hydroarylation or off-cycle species formed by the trapping of a 3-coordinate $\left[\mathrm{L}_{2} \mathrm{Pt}\left(\mathrm{CH}_{2} \mathrm{CH}_{2} \mathrm{Ph}\right)\right]^{+}$intermediate with ethylene. ${ }^{14,19}$ To elucidate the role of such species during catalysis, several stoichiometric reactions with ethylene were performed to generate potential catalytic intermediates. Using a low-pressure J-Young NMR tube ( $3 \mathrm{~mL}$ volume) as a reaction vessel, complex $2 \mathrm{a}$ was treated with ethylene ( $1 \mathrm{~atm}$ ) in benzene- $d_{6}$ at ambient temperatures over a 4 day period and the reaction was monitored by ${ }^{1} \mathrm{H}$ NMR spectroscopy. During the course of the ligand substitution reaction, a mixture of $\mathbf{2 a}$, the ligand substitution product ( $\left.{ }^{t} \mathrm{BuPy} / \mathrm{nd}\right) \mathrm{PtPh}\left(\mathrm{C}_{2} \mathrm{H}_{4}\right)(3)$, and the olefin insertion product ( ${ }^{\mathrm{B}} \mathrm{BuPy}$ Ind) $\mathrm{Pt}\left(\mathrm{CH}_{2} \mathrm{CH}_{2} \mathrm{Ph}\right)\left(\mathrm{C}_{2} \mathrm{H}_{4}\right)(4)$ was observed by ${ }^{1} \mathrm{H}$ NMR spectroscopy after 3 days in a ratio of ca. 1.1:1.0:0.2, respectively (see $\mathrm{SI}$, Figure S9).

Scheme 2. Synthesis of $\mathbf{3}$ from $\mathbf{2 a}$ or Zeise's Dimer.

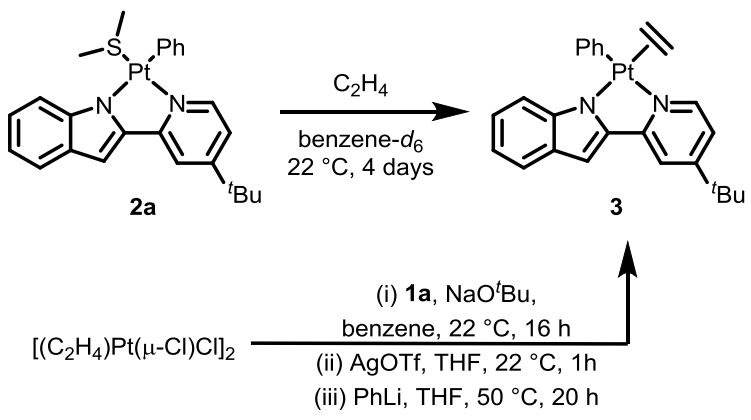


Compound 3 could be purified from the reaction mixture by column chromatography in low yield (isolated yield: $9 \mathrm{mg}$, 29\%). An independent and scalable synthesis of $\mathbf{3}$ (Scheme 2) was accomplished by (i) metallation of Zeise's dimer, $\left[\left(\mathrm{C}_{2} \mathrm{H}_{4}\right) \mathrm{Pt}(\mu-\mathrm{Cl}) \mathrm{Cl}\right]_{2}$, with ${ }^{t} \mathrm{BuPy}$ Ind in the presence of $\mathrm{NaO}^{t} \mathrm{Bu}$, followed by (ii) treatment with AgOTf, and (iii) phenylation with PhLi (isolated yield: $25 \mathrm{mg}, 20 \%$ ). The X-ray structure of 3 (Figure 3) reveals a square planar geometry similar to that of complex 2a, except that in $\mathbf{3}$ the phenyl ligand is cis to the indolate group. Overall, the $\mathrm{Pt}-\mathrm{N}$ and $\mathrm{Pt}-\mathrm{C}$ distances are similar in $\mathbf{2} a$ and $\mathbf{3}$. The $\mathrm{C}-\mathrm{C}$ bond of the bound ethylene ligand in $\mathbf{3}$ $(1.386(6) \AA)$ is slightly elongated compared to free ethylene (1.3305(10) Å). ${ }^{21}$ A broad ethylene resonance with ${ }^{195} \mathrm{Pt}$ satellites was observed in the ${ }^{1} \mathrm{H}$ NMR spectrum of $\mathbf{3}$ in dichloromethane- $d_{2}\left(\delta=3.84 \mathrm{ppm}, J_{\mathrm{PtH}}=60 \mathrm{~Hz}\right)$.

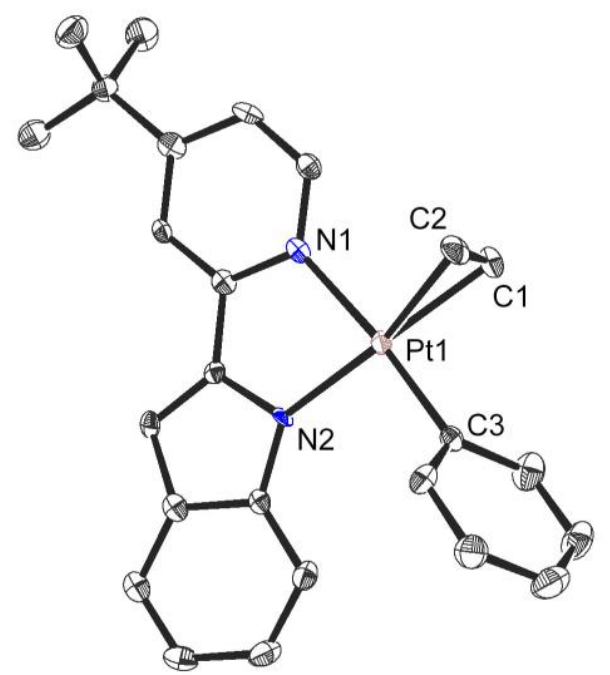

Figure 3. Crystal structure of $\mathbf{3}$, with thermal ellipsoids at $50 \%$ probability and hydrogen atoms omitted. Selected bond lengths $(\AA ̊)$ and angles $\left({ }^{\circ}\right)$ for 3: $\mathrm{C}(1)-\mathrm{C}(2)$ : $1.386(6), \mathrm{C}(1)-\operatorname{Pt}(1)$ : 2.115(4), C(2)-Pt(1): 2.130(4), C(3)-Pt(1): 2.013(4), N(1)-Pt(1): 2.121(3), $\mathrm{N}(2)-\operatorname{Pt}(1): 2.023(3), \mathrm{C}(3)-\mathrm{Pt}(1)-\mathrm{N}(2): 96.37(14), \mathrm{N}(1)-\operatorname{Pt}(1)-$ $\mathrm{N}(2): 79.52(12)$.

Exposure of $2 \mathrm{a}$ to an excess of ethylene at $40^{\circ} \mathrm{C}$ for 10 days cleanly afforded the insertion product 4 after purification via column chromatography in an overall yield of $22 \%$ (eq 2 ). In the ${ }^{1} \mathrm{H}$ NMR spectrum, diagnostic resonances were observed for the two sets of phenethyl methylene protons of 4 at 3.21 $\operatorname{ppm}(\mathrm{t}, J=8.1 \mathrm{~Hz})$ and $2.10 \mathrm{ppm}\left(\mathrm{t}, J_{\mathrm{HH}}=8.2 \mathrm{~Hz}, J_{\mathrm{PtH}}=67 \mathrm{~Hz}\right)$. Additionally, the bound ethylene protons displayed a diagnostic, broadened singlet ${ }^{1} \mathrm{H}$ NMR resonance with ${ }^{195} \mathrm{Pt}$ coupling at $3.00 \mathrm{ppm}\left(\mathrm{s}, J_{\mathrm{PtH}}=54 \mathrm{~Hz}\right)$. The crystal structure of 4 (Figure 4) is similar to those of $\mathbf{2 a}$ and $\mathbf{3}$, with the phenethyl ligand positioned cis to the indolate donor.

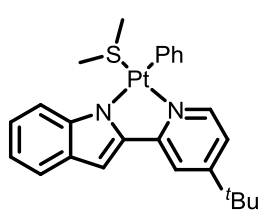

$\mathbf{2 a}$

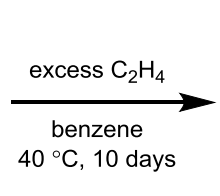
$40^{\circ} \mathrm{C}, 10$ days

5

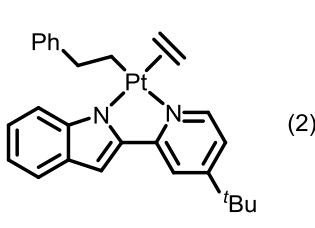

4

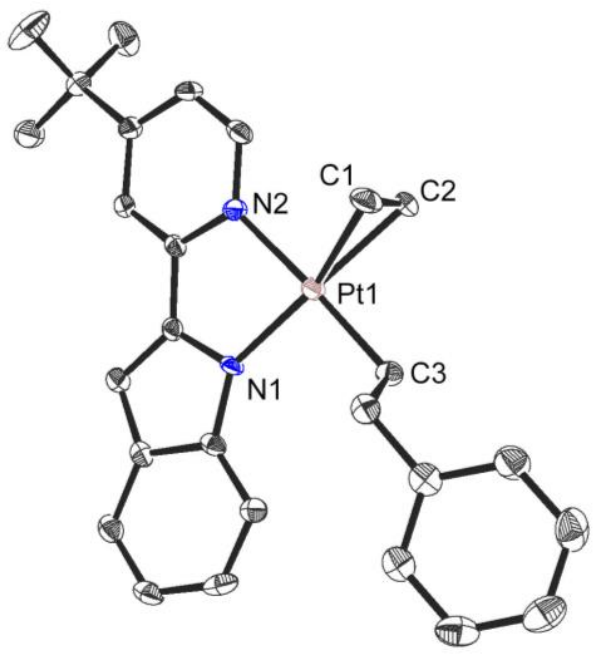

Figure 4. Crystal structure of $\mathbf{4}$, with thermal ellipsoids at $50 \%$ probability and hydrogen atoms omitted. Selected bond lengths $(\AA)$ and angles $\left({ }^{\circ}\right)$ for $4: C(1)-C(2): 1.375(6), C(1)-P t(1): 2.108(4)$, $C(2)-P t(1): 2.104(4), C(3)-P t(1): 2.051(4), N(1)-P t(1): 2.038(3)$, $\mathrm{N}(2)-\mathrm{Pt}(1)$ : 2.134(3), N(1)-Pt(1)-N(2): 76.69(12), N(1)-Pt(1)-C(3): $97.17(14)$.

Thermolysis and Hydroarylation Reactions with Complexes $\mathbf{2 a}, \mathbf{3}$, and $\mathbf{4}$. The stability of complexes $\mathbf{2 a}, \mathbf{3}$, and $\mathbf{4}$ in the absence of olefin was assessed by heating these complexes to $100{ }^{\circ} \mathrm{C}$ in benzene- $d_{6}$ and monitoring changes by ${ }^{1} \mathrm{H}$ NMR spectroscopy. Complex 2a was stable; after $4 \mathrm{~h}$, no change in the ${ }^{1} \mathrm{H}$ NMR spectrum was observed. However, after $46 \mathrm{~h}$ isomerization to a mixture of $\mathbf{2 a}$ and cis-2a was observed by the formation of a second $\mathrm{SMe}_{2}$ resonance as a singlet with ${ }^{195} \mathrm{Pt}-\mathrm{H}$ coupling (see $\mathrm{SI}$, Figure S10). Surprisingly, activation of benzene- $d_{6}$ to form ( $\left.{ }^{t} B u P y \mid n d\right) P t\left(C_{6} D_{5}\right)\left(S M e_{2}\right)$ did not occur. Decomposition to elemental Pt was not visually observed after 46 h.

At $100{ }^{\circ} \mathrm{C}$ in benzene- $d_{6}$, complex 3 rapidly decomposed to elemental Pt, and free ethylbenzene- $d_{1}$ (1 equiv. vs. 3 ) was observed by ${ }^{1} \mathrm{H}$ NMR spectroscopy after $1 \mathrm{~h}$ (see SI, Figure S11). In contrast, heating 4 at $100{ }^{\circ} \mathrm{C}$ for $2 \mathrm{~h}$ resulted in the formation of free ethylene and ethylbenzene- $d_{1}, 0.06$ and 0.3 equiv relative to Pt, respectively (see SI, Figure S12). After $24 \mathrm{~h}$, larger quantities of ethylbenzene- $d_{1}$ were observed, along with the disappearance of resonances corresponding to free ethylene and complex 4. Additionally, elemental Pt was visually observed. This suggests that prior to hydroarylation, the ancillary ethylene ligand of $\mathbf{4}$ must dissociate to provide an open coordination site for $\mathrm{C}-\mathrm{H}$ activation to occur. Complex 4, therefore, is not the active species on the catalytic cycle and is instead an off-cycle intermediate.

The ethylene hydroarylation activities of complexes $\mathbf{3}$ and $\mathbf{4}$ were monitored over $46 \mathrm{~h}$ by ${ }^{1} \mathrm{H}$ NMR spectroscopy to determine the catalytic efficacy of these potential intermediates (Figure 5). Since these complexes lack a strongly coordinating $\mathrm{SMe}_{2}$ ligand, an enhancement in turnovers in comparison to complex 2a was expected. Under catalytic conditions, complexes $\mathbf{2 a}$ and $\mathbf{4}$ displayed similar reaction profiles, with complex $2 \mathrm{a}$ generating ethylbenzene- $d_{6}$ at a slightly faster initial rate. At $24 \mathrm{~h}$, catalytic turnover for complexes $\mathbf{2 a}$ and $\mathbf{4}$ were, 
within error, identical $(7.4 \pm 1.1$ and $7.2 \pm 1.0$ turnovers, respectively). In contrast, complex $\mathbf{3}$ exhibited significantly enhanced initial product formation rates and afforded $12.2 \pm 0.7$ turnovers at $24 \mathrm{~h}$. Interestingly, both $\mathbf{3}$ and $\mathbf{4}$ appeared to be completely inactive after $24 \mathrm{~h}$ whereas $2 \mathrm{a}$ was still minimally competent as a catalyst (albeit at a significantly slower rate). After $46 \mathrm{~h}$, formation of elemental Pt was observed from all three complexes.

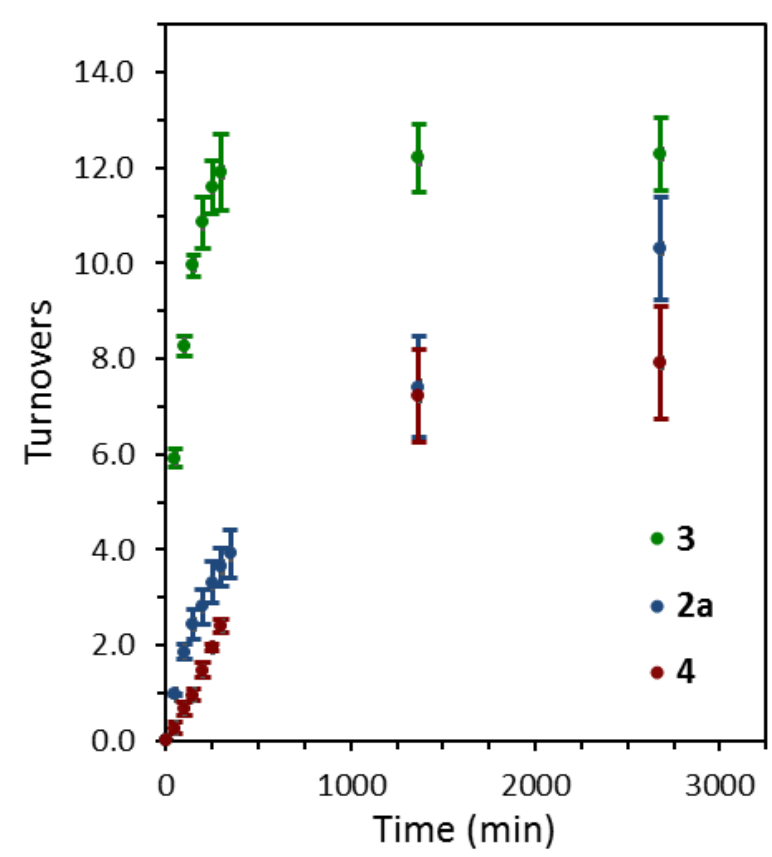

Figure 5. Plot of turnovers of ethylbenzene- $d_{6} v s$. time for catalysts 2a, 3, and 4. Error bars are given as the standard deviation from triplicate experiments.

The effect of L-type ligand concentration on catalysis was explored. Ethylene hydroarylation with benzene- $d_{6}$ using complexes $\mathbf{2 a}$ or $\mathbf{4}$ with 10 equiv of added $\mathrm{SMe}_{2}$ (relative to catalyst) was monitored over $46 \mathrm{~h}$ (see SI, Figure S13). While both $2 \mathrm{a}$ and 4 exhibited minimal turnovers of ethylbenzene- $d_{6}$ after 24 hours, the effect was greater for 2a than 4 ( 0.2 and 1.6 turnovers, respectively). A high ethylene pressure experiment illustrated the qualitative effect of ethylene concentration on catalytic activity. The turnover number of ethylbenzene- $d_{6}$ using $2 \mathrm{a}$ under a constant stream of ethylene at $3 \mathrm{~atm}$ was measured to be 4.1 and is the same, within error, to the turnovers measured with $1 \mathrm{~atm}$ of ethylene (3.6 \pm 0.4$)$. The similar activity at higher ethylene pressure implies a complicated dependence on the concentration of ethylene; it likely both inhibits and promotes fundamental steps during the catalysis, as has been observed by Gunnoe and coworkers ${ }^{14}$ for cationic Pt hydroarylation catalysts.

Since catalysis with $\mathbf{2 a}, \mathbf{3}$, and $\mathbf{4}$ likely proceeds through a common intermediate, variable temperature ${ }^{1} \mathrm{H}$ NMR spectroscopy experiments at $80^{\circ} \mathrm{C}$ were performed in the presence of $1 \mathrm{~atm}$ of ethylene to elucidate the platinum complex speciation during catalysis (see SI, Figures S14-S16). At the initial time point (ca. 3 min of heating) using complex $2 a$ as the precatalyst, complexes $\mathbf{2 a}$ and $\mathbf{3}$ were observed in a 0.83:1.00 ratio, implying that the exchange of $\mathrm{SMe}_{2}$ for ethylene occurs rapidly under catalytic conditions. Interestingly, the insertion product $\mathbf{4}$ was not observed to any appreciable extent over the course of $3 \mathrm{~h}$ at $80^{\circ} \mathrm{C}$. This suggests that $\mathrm{C}-\mathrm{H}$ activation occurs more rapidly than trapping with ethylene, perhaps due to low concentrations of ethylene relative to benzene- $d_{6}$. While the amount of ethylbenzene- $d_{6}$ increased over time, the amount of observed 3 remained relatively constant.

In an analogous experiment with $\mathbf{3}$ as the added precatalyst, rapid ethylbenzene- $d_{6}$ formation was observed, which was accompanied by a slow conversion of $\mathbf{3}$ to $\mathbf{4}$. In a similar experiment using complex 4, reduced activity towards the generation of ethylbenzene- $d_{6}$ was observed. Concurrent formation of complex $\mathbf{3}$ occurred at a slower rate compared to the analogous reaction using $\mathbf{2 a}$ as the precatalyst. These results suggest that ethylene dissociation from complex $\mathbf{4}$ to form a catalytically active species is not rapid.

Testing the Active Catalyst Identity: Base and $\mathrm{Hg}(0)$ Poisoning Experiments. A recent report from this laboratory ${ }^{22}$ demonstrated that the hydroarylation of cyclohexene with mesitylene catalyzed by (COD)Pt(OTf $)_{2}$ proceeds by an acidcatalyzed mechanism, despite the lack of acid as an initial reagent. For this system, an initial metal-mediated olefin coupling $^{23}$ occurs to generate olefin dimers as well as an equivalent of HOTf, which can catalyze hydroarylation via a FriedelCrafts mechanism. The addition of a bulky, non-coordinating base (2,6-di-tert-butyl-4-methylpyridine) reduced catalysis, with complete catalytic inhibition observed upon addition of only two equivalents of base relative to $\mathrm{Pt}$.

To determine whether in situ acid generation caused the observed catalysis with complexes $\mathbf{2 a - k}$, hydroarylation of ethylene with benzene- $d_{6}$ was performed in the presence of 20 equiv of 2,6-di-tert-butyl-4-methylpyridine relative to catalyst 2a. Catalytic activity was monitored by ${ }^{1} \mathrm{H}$ NMR spectroscopy over $46 \mathrm{~h}$ at $100{ }^{\circ} \mathrm{C}$ (see SI, Figure S17). No change in catalytic behavior was observed at any point during catalysis, which suggests that hydroarylation is not the result of adventitious acid-catalysis.

Hydroarylation experiments in the presence of added $\mathrm{Hg}(0)$ were used to elucidate whether the reaction was catalyzed by a soluble species or by a heterogeneous $\mathrm{Pt}(0)$ material formed by in situ decomposition of the molecular precatalysts. ${ }^{24-26}$ Mercury readily forms amalgams with Group 10 metals, which should trap any catalytically active heterogeneous species, assuming the rate of amalgamation is fast relative to catalysis. ${ }^{24}$ To this end, addition of $\mathrm{Hg}(0)$ has been employed as a poison for adventitious nanoparticle catalyzed reactions. ${ }^{25}$ As a result, if nanoparticles are indeed the catalytically active species then the inclusion of $\mathrm{Hg}(0)$ into the reaction mixture should inhibit product formation (assuming a fast rate of amalgamation). ${ }^{24,25}$

Hydroarylation of ethylene with benzene- $d_{6}$, with 2 a or 3 as catalysts, was performed in the presence of $\mathrm{Hg}(0)$ and product formation was monitored over a 5 day period (see SI, Figure S18). Surprisingly, catalytic activity for both $\mathbf{2 a}$ and $\mathbf{3}$ was improved with the addition of $\mathrm{Hg}$ (15.7 and 24.3 turnovers after $24 \mathrm{~h}$ at $100{ }^{\circ} \mathrm{C}$ in the presence of $\mathrm{Hg}(0)$ vs 7.8 and 12.2 turnovers in its absence, respectively). Moreover, decomposition rates were reduced in the presence of $\mathrm{Hg}$. To elucidate the 
cause for the improved performance, several further control experiments were performed.

To probe the existence of possible molecular $\mathrm{Hg}$-Pt adducts which could be more catalytically active than the initial precatalysts, complex $2 \mathrm{a}$ was heated to $100{ }^{\circ} \mathrm{C}$ in benzene- $d_{6}$ with added mercury in the absence of ethylene. No change in the ${ }^{1} \mathrm{H}$ NMR spectrum was observed, which suggests that in the absence of olefin, $\mathrm{Hg}$ and $\mathbf{2 a}$ do not interact to form a detectable species. Additionally, catalysts $\mathbf{2 a}$ or $\mathbf{3}$ were prestirred in benzene- $d_{6}$ with $\mathrm{Hg}(0)$, carefully filtered, and then subjected to standard hydroarylation conditions (see SI, Figure S19). Catalyst 3 did not exhibit a change in activity compared to catalysis without prestirring with $\mathrm{Hg}(0)$. In contrast, complex $\mathbf{2 a}$ demonstrated a slight improvement in catalytic activity (albeit less so than in the presence of $\mathrm{Hg}$ ). It has been reported that metallic nanoparticles can grow by an autocatalytic mechanism involving an acceleration of the conversion rate for molecular precursors after nucleation. ${ }^{26}$ Therefore, we propose that sequestration of $\mathrm{Pt}(0)$ seed particles via amalgamation with $\mathrm{Hg}(0)$ results in reduced competitive decomposition rates and therefore an improvement to catalyst stability and longevity.

Proposed Hydroarylation Mechanism. Given the observations above, a mechanism for ethylene hydroarylation similar to those reported by Gunnoe ${ }^{14}$ and Goldberg ${ }^{15}$ is proposed (Figure 6). An equilibrium between the dimethylsulfide precatalyst $\mathbf{2} \mathbf{a}$ and the active species $\mathbf{3}$ occurs via a rapid ligand exchange with ethylene. Olefin insertion into the $\mathrm{Pt}-\mathrm{Ph}$ bond yields a coordinatively unsaturated ( $\left.{ }^{\mathrm{B}} \mathrm{BuPy} \operatorname{lnd}\right) \mathrm{Pt}\left(\mathrm{CH}_{2} \mathrm{CH}_{2} \mathrm{Ph}\right.$ ) species (A), likely stabilized by either an agostic interaction of the 8 -phenethyl $\mathrm{C}-\mathrm{H}$ bond or a $\pi$-interaction of the phenethyl arene with the Pt center. Computations for analogous cationic $P t$ complexes suggest that a $\pi$-interaction is more stable than an agostic interaction, resulting in a larger kinetic barrier for $\mathrm{C}-$ $\mathrm{H}$ activation from the $\pi$-complex $\left(\Delta \Delta \mathrm{G}^{\ddagger}=5.0 \mathrm{kcal} / \mathrm{mol}\right) \cdot{ }^{14}$ Therefore, it is quite possible that the agostic complex is the catalytically relevant intermediate, $\mathbf{A}$.

Intermediate $\mathbf{A}$ induces arene $\mathrm{C}-\mathrm{H}$ activation of solvent by an oxidative addition reaction to form a five-coordinate, $\mathrm{Pt}^{\mathrm{I}}$ hydride intermediate (B). Subsequent reductive elimination from $\mathbf{C}$, and exchange of the bound ethylbenzene ligand for ethylene, regenerates 3 . Alternatively, $\mathrm{C}-\mathrm{H}$ activation can occur by a $\sigma$-bond metathesis mechanism to form ethylbenzene in a single step. Recent precedent for this type of mechanism has been published by the Gunnoe ${ }^{14}$ and Cundari ${ }^{19}$ groups. For cationic Pt species, DFT calculations suggest that a two-step oxidative addition/reductive elimination pathway is only slightly preferred over a $\sigma$-bond metathesis route $\left(\Delta \Delta \mathrm{G}^{\ddagger}=2.3\right.$ $\mathrm{kcal} / \mathrm{mol}) \cdot{ }^{14,19}$

It has been suggested by Gunnoe and coworkers ${ }^{14}$ that complexes of the type $\left[(\mathrm{bpy}) \mathrm{Pt}\left(\mathrm{CH}_{2} \mathrm{CH}_{2} \mathrm{Ph}\right)\left(\mathrm{C}_{2} \mathrm{H}_{4}\right)\right]^{+}$are either catalytic intermediates or off-cycle species. Since complex 4 exhibits reduced hydroarylation activity compared to $\mathbf{2 a}$ or $\mathbf{3}$, and releases ethylene upon heating in benzene, it seems likely that this complex exists as an off-cycle intermediate in equilibrium with A via ethylene dissociation.

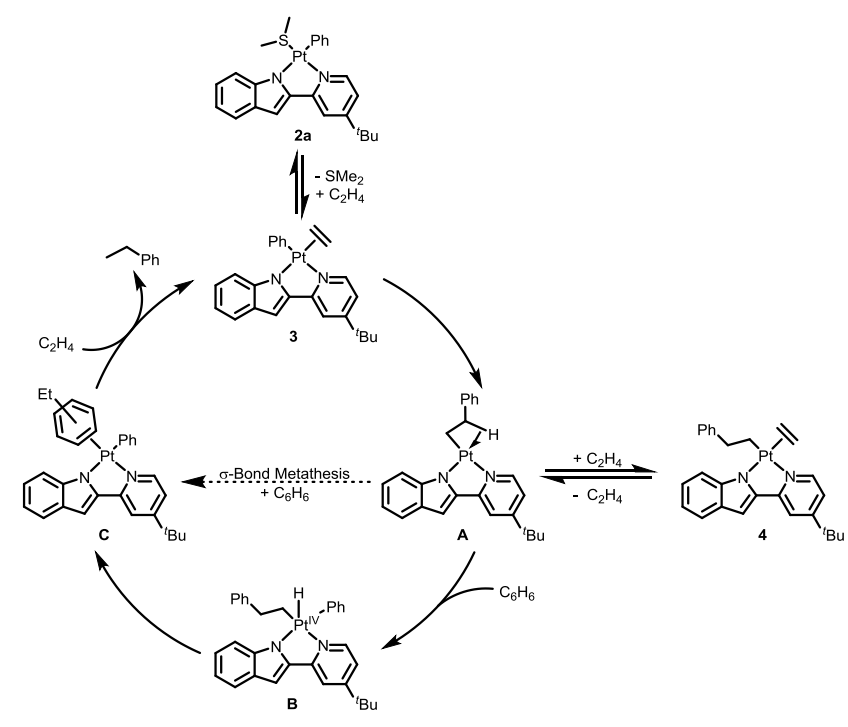

Figure 6. Proposed mechanism for productive catalytic ethylene hydroarylation with $\mathbf{2 a}$. Note that $\mathrm{C}-\mathrm{H}$ bond activation can occur via either an oxidative addition/reductive elimination or $\sigma$-bond metathesis pathway.

Catalyst Decomposition Studies. While olefin hydroarylation is catalyzed by $(\mathrm{N}-\mathrm{N})$-ligated Pt complexes, the stability of these catalytic species appears to be the major factor in defining catalytic efficiency (vide supra). In an effort to understand the decomposition pathways available during catalysis, a sample of 2a was exposed to benzene and ethylene (1 atm) at 100 ${ }^{\circ} \mathrm{C}$ for $20 \mathrm{~h}$, and products were separated from elemental Pt by preparative thin-layer chromatography. Several species were identified by high resolution mass spectrometry (see Figure 7 and $\mathrm{SI}$, Table S1). Organic species with $\mathrm{m} / \mathrm{z}$ values consistent with free ligand (1a) and phenethyl substituted ${ }^{t}$ BuPyInd (5) were identified. Complexes $\mathbf{2} \mathbf{a}$ and $\mathbf{3}$ were also observed. Surprisingly, $m / z$ values that correspond to previously unobserved organometallic compounds were also detected: [( ${ }^{t} \mathrm{Bu}$ Pylnd)Pt $\left.\left(\mathrm{CH}_{2} \mathrm{CH}_{2} \mathrm{Ph}\right)\left(\mathrm{SMe}_{2}\right)\right]$ (6), [( $\left.{ }^{\text {B BuPyInd }) P t E t}\left(\mathrm{SMe}_{2}\right)\right]$ (7), and [( ${ }^{t} \mathrm{BuPy}$ Ind) $\left.\mathrm{PtPh}\left(\mathrm{H}_{2} \mathrm{C}=\mathrm{CHPh}\right)\right]$ (8). While relative amounts could not be quantified with high resolution mass spectrometry, the existence of these species suggests possible decomposition pathways.

Since styrene has been implied as a major decomposition product, $14,15,18$ a separate ethylene hydroarylation experiment was performed at $100^{\circ} \mathrm{C}$ for $24 \mathrm{~h}$ and styrene content was determined by ${ }^{1} \mathrm{H}$ NMR spectroscopy. Unreacted ethylene was removed by a freeze/pump/thaw cycle, since ethylene and styrene vinylic resonances overlap. Multiple sets of vinylic resonances are consistent with styrene, 6 - $(E)$-deuterostyrene, and $B$-(Z)-deuterostyrene. The relative ratio of these three species (with respect to the initial catalyst loading) was ca. $10 \%: 8 \%: 12 \%$, respectively.

Given these data, possible catalyst decomposition pathways are described in Figure 7. As in the productive hydroarylation mechanism (Figure 6), ligand exchange with ethylene from complex $2 \mathbf{a}$ affords the ethylene complex $\mathbf{3}$ and subsequent insertion yields intermediate $\mathbf{A}$. This intermediate is undoubtedly trapped by available L-type ligands (i.e. ethylene or $\mathrm{SMe}_{2}$ ) to afford complexes $\mathbf{4}$ and $\mathbf{6}$. These species can reenter 

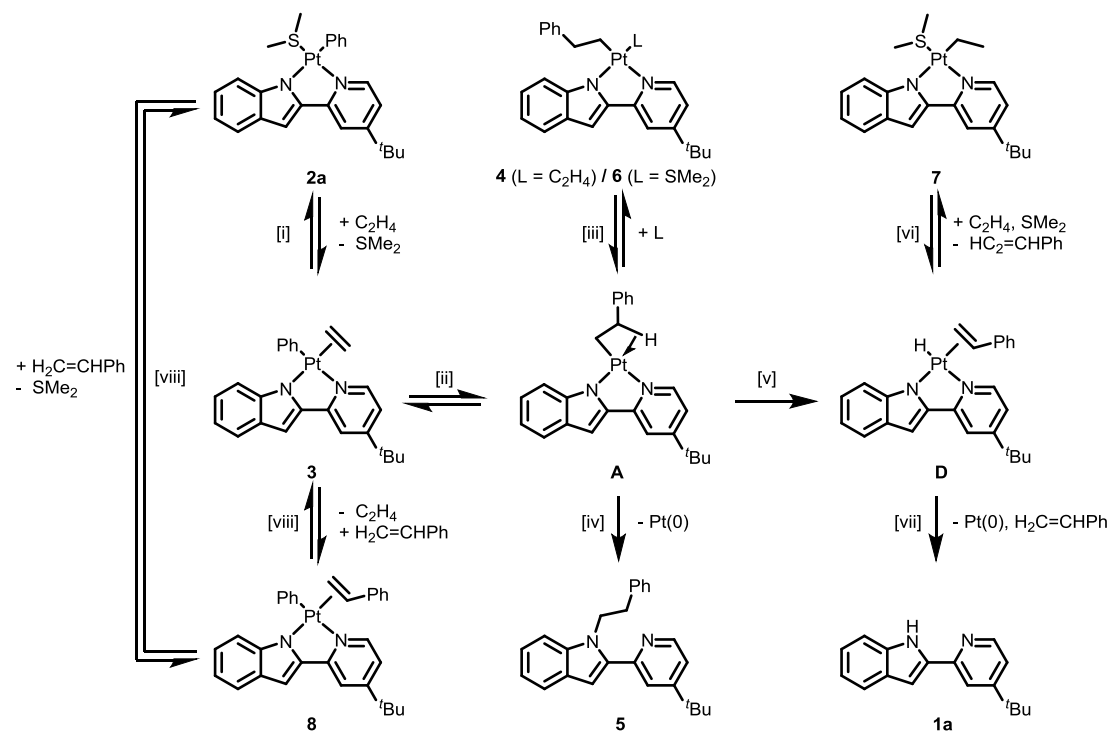

Figure 7. Organometallic speciation and decomposition pathways in ethylene hydroarylation with benzene and catalyst $2 \mathrm{a}$. [i]: ligand substitution for ethylene; [ii]: olefin insertion; [iii]: coordination of either $\mathrm{SMe}_{2}$ or ethylene; [iv]: reductive elimination of phenethyl and ${ }^{t}$ BuPylnd; [v]: 6-hydride elimination; [vi]: ligand substitution of styrene for ethylene, followed by olefin insertion and coordination of SMe ${ }_{2}$; [vii]: reductive elimination of hydride and ${ }^{t}$ BuPylnd; [viii]: ligand substitution of $\mathrm{SMe}_{2}$ for styrene.

the catalytic cycle, but as shown above they are less effective than $\mathbf{3}$ and do not directly participate in the major catalytic cycle.

While $\mathbf{A}$ can undergo reaction to produce ethylbenzene (Figure 6), it may also be a key intermediate in catalyst decomposition. Intermediate $\mathbf{A}$ can undergo irreversible decomposition by reductive elimination of the phenethyl fragment with the ${ }^{t}$ BuPyInd ligand, which results in the formation of $\mathrm{Pt}(0)$ and $\mathbf{5}$. Alternatively, $b$-hydride elimination from the phenethyl fragment can occur to generate a transient Pt-hydride complex $\mathbf{D}$ bearing a styrene ligand. Precedent for this decomposition route exists and has been supported by DFT calculations for cationic Pt systems. ${ }^{14}$ B-Agostic intermediates of the type $\left[\left({ }^{t} \mathrm{bpy}\right) \mathrm{Pt}\left(\mathrm{CH}_{2} \mathrm{CH}_{2} \mathrm{Ph}\right)\right]^{+}$have been calculated to contain a shortened $\mathrm{C}_{\mathrm{sp} 3}-\mathrm{C}_{\mathrm{sp} 3}$ bond distance, which is consistent with partial $\left[{ }^{t}\right.$ bpy $) \mathrm{PtH}($ styrene $\left.)\right]^{+}$character. Therefore, it is unsurprising that the Pt-hydride intermediate $\mathbf{A}$ likely undergoes a facile $\boldsymbol{B}$ hydride elimination to afford $\mathbf{D}$. Reductive elimination can occur from $\mathbf{D}$ to generate free ligand (1a) as well as an equivalent of styrene and $\mathrm{Pt}(0)$. Goldberg and coworkers ${ }^{15,18}$ have observed styrene formation via 6 -hydride elimination as the primary decomposition pathway for a similar pyridyl-pyrrole ligated Pt(II) system. Given the existence of multiple styrene isotopomers and that the catalysis primarily affords ethylbenzene- $d_{6}, H(D)$ scrambling likely occurs from complex $D$ and not a catalytically active species.

In a recent publication by Nozaki ${ }^{27}$, complexes of the type $[(\mathrm{P}-\mathrm{O}) \mathrm{PtPh}(\mathrm{L})]$ supported by a 2-(di-tert-butylphosphanyl)benzenesulfonate ligand were employed as precursors in the generation of stable Pt-hydride species by treatment with ethylene. Olefin insertion from these PtPh complex was suggested to generate a $\mathrm{Pt}\left(\mathrm{CH}_{2} \mathrm{CH}_{2} \mathrm{Ph}\right)$ fragment, although such species were not directly observed. Moreover, $\mathrm{C}-\mathrm{H}$ activation to form ethylbenzene was not observed. Instead, a favorable B-hydride elimination event occurred to generate $[(\mathrm{P}-\mathrm{O}) \mathrm{PtH}$ (styrene)] as an isolable species capable of catalytic olefin polymerization. This suggests that the donating properties of the supporting ligand greatly affect the stabilities of intermediates during productive hydroarylation and catalyst decomposition processes; stabilization of Pt-hydride species prevents irreversible ligand reductive elimination while also favoring unproductive $\mathrm{B}$-hydride elimination over $\mathrm{C}-\mathrm{H}$ activation.

Complex $\mathbf{D}$ can also undergo ligand substitution of styrene for ethylene. Hydride migration to the bound ethylene can occur followed by coordination of an L-type ligand to generate the Pt(II)-ethyl complex 7. Similar Pt-ethyl complexes have been identified as off-cycle organometallic products by the Gunnoe group ${ }^{14}$ for cationic ('bpy)Pt complexes. Finally, complex 2a can also undergo ligand substitution with any styrene generated during the course of decomposition to afford the styrene-bound complex $\mathbf{8}$. These data suggest that a series of common mechanistic steps occur to produce the observed organometallic side-products, organic decomposition species, and elemental Pt: 6 -hydride elimination, olefin (or residual sulfide) binding at platinum, and reductive elimination involving the $(\mathrm{N}-\mathrm{N})$ ligand.

\section{CONCLUSIONS}

In summary, a series of Pt(II) catalysts featuring bidentate pyridyl-indolate ligands with varying substituents has been successfully synthesized. These complexes demonstrated the ability to catalyze olefin hydroarylation on a range of substrates. In general, complexes of the type $(\mathrm{N}-\mathrm{N}) \mathrm{PtPh}\left(\mathrm{SR}_{2}\right)$ exhibited reasonable activity compared to other reported $\mathrm{Pt}$ complexes. ${ }^{14,15}$ Additionally, reduced over-alkylation was observed using the current catalysts.

Two potential intermediates ( 3 and $\mathbf{4}$ ) were isolated and their activities were compared with that of precatalyst $\mathbf{2 a}$. Complex 3 , bearing Ph and $\mathrm{C}_{2} \mathrm{H}_{4}$ as ancillary ligands, rapidly catalyzed olefin hydroarylation. In contrast to complexes $2 \mathbf{a}$ and 3, the aforementioned complex ( ${ }^{\mathrm{B}} \mathrm{BuPy}$ Ind) $\mathrm{Pt}\left(\mathrm{CH}_{2} \mathrm{CH}_{2} \mathrm{Ph}\right)\left(\mathrm{C}_{2} \mathrm{H}_{4}\right)$ 
exhibited reduced activity and therefore is not a direct catalytic intermediate in this system: ethylene dissociation is required for catalysis to occur. Interestingly, complex 2a exhibited improved catalytic stability when compared to $\mathbf{3}$ or $\mathbf{4}$, which suggests that the ancillary $\mathrm{SMe}_{2}$ ligand retards decomposition at the expense of reduced activity.

Several studies were designed to probe the operative mechanism for catalysis. We have shown that efficiency in this platinum system is determined primarily by competing, irreversible catalyst decomposition. The competitive decomposition routes were studied to better understand how to combat poor catalytic stability. Many different organometallic and organic species were identified after completion of the catalysis; the organometallic complexes could likely reenter the catalytic cycle while the organic fragments arise from irreversible reductive eliminations. Unproductive 6 -hydride elimination is a major issue for catalytic stability due to the ease with which irreversible reductive elimination occurs from $\mathrm{Pt}$-hydride species to form free ligand and elemental Pt. Moreover, the competing processes of catalyst turnover and decomposition involve ( ${ }^{t} \mathrm{Bu}$ Pylnd) $\mathrm{Pt}\left(\mathrm{CH}_{2} \mathrm{CH}_{2} \mathrm{Ph}\right)$ as a key, common intermediate. Therefore, further improvements in efficiencies of Pt-based hydroarylation catalysts should focus on improving the stabilities of catalytic intermediates, especially toward $B$-hydride eliminations.

External base and $\mathrm{Hg}(0)$ tests revealed that hydroarylation is metal mediated rather than adventitiously catalyzed either by acid generated in situ or elemental Pt nanoparticles. Interestingly, this study uncovered a potential additive in catalysis (elemental $\mathrm{Hg}$ ) that seemingly suppresses catalyst decomposition and allows for longer catalyst lifetimes. ${ }^{24-26}$ This surprising inhibition of catalytic decomposition is an interesting feature of this system, which provides a potential solution to one of the major dilemmas in Pt catalyzed hydroarylation: competitive catalytic decomposition. While only $\mathrm{Hg}(0)$ has been employed in this study towards decomposition suppression, it may be possible that other additives can effectively sequester nucleating Pt nanoparticles and thereby prevent autocatalytic decay of hydroarylation catalysts.

\section{ASSOCIATED CONTENT}

\section{Supporting Information}

Experimental details, characterization data, X-ray crystallographic details, and CIF files. This material is available free of charge via the Internet at http://pubs.acs.org.

\section{AUTHOR INFORMATION}

\section{Corresponding Author}

*E-mail: tdtilley@berkeley.edu

Present Address

${ }^{\ddagger}$ A.L.L.-M.: Division of Chemistry and Chemical Engineering, California Institute of Technology, 1200 East California Blvd, Pasadena, CA, 91125.

ORCID

Benjamin A. Suslick: 0000-0002-6499-3625

Allegra L. Liberman-Martin: 0000-0002-8447-905X

Truman C. Wambach: 0000-0001-7384-0412

T. Don Tilley: 0000-0002-6671-9099
Notes

The authors declare no competing financial interests.

\section{ACKNOWLEDGMENT}

This work was primarily funded by the U.S. Department of Energy, Office of Science, Office of Basic Energy Sciences, Chemical Sciences, Geosciences, and Biosciences Division under Contract No. DE-AC02-05CH11231. We acknowledge the NIH (Grant Nos. SRR023679A, 1S10RR016634-01) and NSF (Grant No. CHE0130862) for funding of the College of Chemistry NMR facility (University of California, Berkeley). The Central California $900 \mathrm{MHz}$ NMR Facility (University of California, Berkeley) is acknowledged for providing access to the $900 \mathrm{MHz}$ NMR spectrometer, and is supported by the NIH (GM68933). The QB3/Chemistry Mass Spectrometry Facility (University of California, Berkeley) is acknowledged for help and access to the LTQ-FT ESI-HRMS (SN 06053F) and AutoSpec El-HRMS (SN P749, property ID\# 20081000740) instruments. We also acknowledge the NIH (Grant No. S10RR027172) for funding of the ChexRay X-ray crystallographic facility (College of Chemistry, University of California, Berkeley). B.A.S. acknowledges the NSF-GRFP for a fellowship (DGE 1106400). We thank Dr. Michael I. Lipschutz for X-ray structure determinations of 2a-c, 3 and 4. Dr. Jeffery G. Pelton and Dr. Hasan Celik are thanked for help high-field NMR spectroscopy experiments. Dr. Jeffery C. Holder is thanked for help with quantitative GC analysis. Professor Robert G. Bergman, Dr. Nicholas A. Phillips, Dr. Daniel S. Levine, Patrick W. Smith, and Micah S. Ziegler are thanked for providing useful discussions and insights.

\section{REFERENCES}

(1) (a) Welch, V. A.; Fallon, K. J.; Gelbke, H.-P. Ullmann's Encyclopedia of Industrial Chemistry 2005, 13, 451-464; (b) James, D. H.; Castor, W. M. Ullmann's Encyclopedia of Industrial Chemistry 2011, 34, 529544; (c) Maul, J.; Frushour, B. G.; Kontoff, J. R.; Eichenauer, H.; Ott, K.H.; Schade, C. Ullmann's Encyclopedia of Industrial Chemistry 2007, 29, 475-522.

(2) (a) Hartwig, J. F. Organotransition Metal Chemistry: From Bonding to Catalysis; University Science Books: United States, 2010; pp 877-965; (b) Kambe, N.; Iwasaki, T.; Terao, J. Chem. Soc. Rev. 2011, 40, 4937-4947.

(3) (a) Activation and Functionalization of $\mathrm{C}-\mathrm{H}$ Bonds; Goldberg, K. I., Goldman, A. S., Eds.; ACS Symposium Series 885; American Chemical Society: Washington, DC, 2004; (b) Lersch, M.; Tilset, M. Chem. Rev. 2005, 105, 2471-2526; (c) Colby, D. A.; Tsai, A. S.; Bergman, R. G.; Ellman, J. A. Acc. Chem. Res. 2012, 45, 814-825; (d) DeMott, J. C.; Bhuvanesh, N.; Ozerov, O. V. Chem. Sci. 2013, 4, 642-649.

(4) (a) Andreatta, J. R.; McKeown, B. A.; Gunnoe, T. B. J. Organomet. Chem. 2011, 696, 305-315; (b) Chianese, A. R.; Lee, S. J.; Gagné, M. R. Angew. Chem. Int. Ed. 2007, 46, 4042-4059; (c) Moseloge, M.; Li, J.; Ackermann, L. ACS. Catal. 2016, 6, 498-525.

(5) (a) Kakiuchi, F.; Murai, S. Acc. Chem. Res. 2002, 35, 826-834; (b) Murai, S.; Kakiuchi, F.; Sekine, S.; Tanaka, Y.; Kamatani, A.; Sonoda, M.; Chatani, N. Nature 1993, 365, 529-531; (c) Kakiuchi, F.; Kochi, T.; Mizushima, E.; Murai, S. J. Am. Chem. Soc. 2010, 132, 17741-17750.

(6) (a) Foley, N. A.; Lee, J. P; Ke, Z.; Gunnoe, T. B.; Cundari, T. R. Acc. Chem. Res. 2009, 42, 585-597; (b) Lee, J. P; Jimenez-Halla, J. O. C.; Cundari, T. R.; Gunnoe, T. B. J. Organomet. Chem. 2007, 692, 21752186; (c) Foley, N. A.; Lail, M.; Lee, J. P.; Gunnoe, T. B.; Cundari, T. R.; Petersen, J. L. J. Am. Chem. Soc. 2007, 129, 6765-6781; (d) Foley, N. A.; Lail, M.; Gunnoe, T. B.; Cundari, T. R.; Boyle, P. D.; Petersen, J. L. Organometallics 2007, 26, 5507-5516; (e) Kumar, N. Y. P; Bechtoldt, A.; Raghuvansi, K.; Ackermann, L. Angew. Chem. Int. Ed. 2016, 55, 6929-6932; (f) Schinkel, M.; Wallbaum, J.; Kozhushkov, S. I.; Marek, I.; Ackermann, L. Org. Lett. 2013, 15, 4482-4484. 
(7) (a) Matsumoto, T.; Taube, D. J.; Periana, R. A.; Taube, H.; Yoshida, H. J. Am. Chem. Soc. 2000, 122, 7414-7415; (b) Periana, R. A.; Liu, X. Y.; Bhalla, G. Chem. Commun. 2002, 3000-3001; (c) Bhalla, G.; Oxgaard, J.; Goddard, W. A., III; Periana, R. A. Organometallics 2005, 24, 3229-3232; (d) Oxgaard, J.; Muller, R. P.; Goddard, W. A., III; Periana, R. A. J. Am. Chem. Soc. 2004, 126, 352-363; (e) Oxgaard, J.; Periana, R. A.; Goddard, W. A., III. J. Am. Chem. Soc. 2004, 126, 11658-11665.

(8) (a) Crisenza, G. E. M.; McCreanor, N. G.; Bower, J. F. J. Am. Chem. Soc. 2014, 136, 10258-10261. (b) Ebe, Y.; Nishimura, T. J. Am. Chem. Soc. 2015, 137, 5899-5902. (c) Sevov, C. S.; Hartwig, J. F. J. Am. Chem. Soc. 2013, 135, 2116-2119.

(9) (a) Vaughn, B. A.; Webster-Gardiner, M. S.; Cundari, T. R.; Gunnoe, T. B. Science 2015, 248, 421-424; (b) Webster-Gardiner, M. S.; Fu, R.; Fortman, G. C.; Nielsen, R. J.; Gunnoe, T. B.; Goddard, W. A., III. Catal. Sci. Technol. 2015, 5, 96-100; (c) Webster-Gardiner, M. S.; Piszel, P. E.; Fu, R.; McKeown, B. A.; Nielsen, R. J.; Goddard, W. A., III; Gunnoe, T. B. J. Mol. Catal. A: Chem. 2017, 426, 381-388; (d) Vaughan, A. B.; Khani, S. K.; Gary, J. B.; Kammert, J. D.; Webster-Gardiner, M. S.; McKeown, B. A.; Davis, R. J.; Cundari, T. R.; Gunnoe, T. B. J. Am. Chem. Soc. 2017, 139, 1485-1498.

(10) (a) Filloux, C. M.; Rovis, J. Am. Chem. Soc. 2015, 137, 508-517; (b) Harada, H.; Thalji, R. K.; Bergman, R. G.; Ellman, J. A. J. Org. Chem. 2008, 73, 6772-6779; (c) Jun, C.-H.; Hong, J.-B.; Kim, Y.-H.; Chung, K.Y. Angew. Chem. Int. Ed. 2000, 39, 3440-3442; (d) Lim, S.-G.; Ahn, J.A.; Jun, C.-H. Org. Lett. 2004, 6, 4687-4690; (e) Ryu, J.; Cho, S. H.; Chang, S. Angew. Chem. Int. Ed. 2012, 51, 3677-3681; (f) Sun, Z. M.; Zhang, J.; Manan, R. S.; Zhao, P. J. Am. Chem. Soc. 2010, 132, 69356937; (g) Tsui, G. C.; Menard, F.; Lautens, M. Org. Let. 2010, 12, $2456-$ 2459.

(11) (a) Podhajsky, S. M.; Iwai, Y.; Cook-Sneathen, A.; Sigman, M. S. Tetrahedron 2011, 67, 4435-4441; (b) Cacchi, S. Pure \& Appl. Chem. 1990, 62, 713-722.

(12) McKeown, B. A.; Foley, N. A.; Lee, J. P.; Gunnoe, T. B. Organometallics 2008, 27, 4031-4033.

(13) Luedtke, A. T.; Goldberg, K. I. Inorg. Chem. 2007, 46, 8496-8498.

(14) McKeown, B. A; Gonzalez, H. E.; Friedfeld, M. R; Gunnoe, T. B.; Cundari, T. R.; Sabat, M. J. Am. Chem. Soc. 2011, 133, 19131-19152.
(15) Luedtke, A. T.; Goldberg, K. I. Angew. Chem. Int. Ed. 2008, 47, 7694-7696.

(16) (a) Karshtedt, D.; Bell, A. T.; Tilley, T. D. Organometallics 2004, 23, 4169-4171; (b) Karshtedt, D.; McBee, J. L.; Bell, A. T.; Tilley, T. D. Organometallics 2006, 25, 1801-1811.

(17) Liu, Q.-D.; Mudadu, M. S.; Thummel, R.; Tao, Y.; Wang, S. Adv. Func. Mater. 2005, 15, 143-154.

(18) Clement, M. L.; Grice, K. A.; Luedtke, A. T.; Kaminsky, W.; Goldberg, K. I. Chem. Eur. J. 2014, 20, 17287-17291.

(19) (a) Cundari, T. R.; Gonzalez, H. E. J. Mol. Catal. A.: Chem.2012, 353-354, 1-6; (b) McKeown, B. A.; Gonzalez, H. E.; Michaelos, T.; Gunnoe, T. B.; Cundari, T. R.; Crabtree, R. H.; Sabat, M. Organometallics 2013, 32, 3903-3913; (c) McKeown, B. A.; Gonzalez, H. E.; Gunnoe, T. B.; Cundari, T. R.; Sabat, M. ACS Catal. 2013, 3, 1165-1171.

(20) Simmons, E. M.; Hartwig, J. F. Angew. Chem. Int. Ed. 2012, 51, 3066-3072.

(21) Craig, N. C.; Groner, P.; McKean, D. C. J. Phys. Chem. A 2006, 110, 7461-7469.

(22) Bowring, M. A.; Bergman, R. G.; Tilley, T. D. Organometallics 2011, 30, 1295-1298.

(23) Szuromi, E.; Sharp, P. R. Organometallics 2006, 25, 558-559.

(24) Widegren, J. A.; Finke, R. G. J. Mol. Catal. A: Chem. 2003, 198, 317-341.

(25) (a) Whitesides, G. M.; Hackett, M.; Brainard, R. L.; Lavalleye, J.P. P. M.; Sowinski, A. F.; Izumi, A. N.; Moore, S. S.; Brown, D. W.; Staudt, E. M. Organometallics 1985, 4, 1819-1830; (b) Bayram, E.; Linehan, J. C.; Fulton, J. K.; Szymczak, N. K.; Finke, R. G. ACS Catal. 2015, 5, 3876-3886; (c) Hagen, C. M.; Widegren, J. A.; Maitlis, P. M.; Finke, R. G. J. Am. Chem. Soc. 2005, 127, 4423-4432.

(26) (a) Naqvi, K. R.; Marsh, J.; Chechik, V. Dalton Trans. 2014, 43, 4745-4751; (b) Kent, P. D.; Mondloch, J. E.; Finke, R. G. J. Am. Chem. Soc. 2014, 136, 1930-1941; (c) Besson, C.; Finney, E. C.; Finke, R. G. J. Am. Chem. Soc. 2005, 127, 8179-8184.

(27) Pal, S.; Kusumoto, S.; Nozaki, K. Organometallics 2017, 36, 502505. 